\title{
Impact of tiotropium + olodaterol on physical functioning in COPD: results of an open-label observational study
}

This article was published in the following Dove Press journal:

International Journal of COPD

27 April 2016

Number of times this article has been viewed

\author{
Rüdiger Sauer ${ }^{\prime}$ \\ Michaela Hänsel ${ }^{2}$ \\ Roland Buhl ${ }^{3}$ \\ Roman A Rubin ${ }^{4}$ \\ Marcel Frey ${ }^{5}$ \\ Thomas Glaab 2,3 \\ 'Lung Centre Ulm, Ulm, Germany; \\ ${ }^{2}$ Boehringer Ingelheim Pharma \\ GmbH \& Co. KG, Ingelheim, Germany; \\ ${ }^{3}$ Pulmonary Department, Mainz \\ University Hospital, Mainz, Germany; \\ ${ }^{4}$ Pulmonary Specialist Practice, \\ Wiesbaden, Germany; ${ }^{5}$ Biometrics, \\ Alcedis $\mathrm{GmbH}$, Gießen, Germany
}

Correspondence: Thomas Glaab Boehringer Ingelheim Pharma GmbH \& Co. KG, Medical Affairs Germany, Respiratory Medicine, Binger Strasse 173, D-55216 Ingelheim am Rhein, Germany Tel +496132773344

Fax +496132723344

Email thomas.glaab@boehringer-

ingelheim.com
Background: Maintaining and improving physical functioning is key to mitigating the cycle of deconditioning associated with chronic obstructive pulmonary disease (COPD). We evaluated the impact of free combination of the long-acting anticholinergic tiotropium plus the long-acting $\beta_{2}$-agonist olodaterol on physical functioning in a real-world clinical setting.

Methods: In this open-label noninterventional study, Global initiative for chronic Obstructive Lung Disease (GOLD) B-D patients with COPD aged $\geq 40$ years were treated for 4-6 weeks with either tiotropium $5 \mu \mathrm{g}$ + olodaterol $5 \mu \mathrm{g}$ (both via Respimat ${ }^{\circledR}$ inhaler) or tiotropium $18 \mu \mathrm{g}$ $\left(\right.$ HandiHaler $\left.^{\circledR}\right)+$ olodaterol $5 \mu \mathrm{g}\left(\right.$ Respimat $\left.^{\circledR}\right)$ once daily. Physical functioning was assessed by the self-reported 10-item Physical Functioning Questionnaire (PF-10). The primary end point was the percentage of patients achieving therapeutic success, defined as a 10-point increase in the PF-10 between baseline (visit 1) and weeks 4-6 (visit 2). Secondary end points included absolute PF-10 scores, Physicians' Global Evaluation, satisfaction with Respimat ${ }^{\mathbb{B}}$ and adverse events.

Results: A total of 1,858 patients were treated: 1,298 (69.9\%) with tiotropium $5 \mu \mathrm{g}+$ olodaterol $5 \mu \mathrm{g}$ and $560(30.1 \%)$ with tiotropium $18 \mu \mathrm{g}+$ olodaterol $5 \mu \mathrm{g}$. At study end, 1,683 (92.6\%) and 1,556 patients $(85.6 \%)$ continued using tiotropium and olodaterol, respectively; $48.9 \%$ ( $95 \%$ confidence interval: $46.5,51.3$ ) achieved the primary end point. Therapeutic success rates were significantly higher for maintenance-naïve patients compared to those who had received prior therapy ( $59.1 \%$ vs $44.5 \% ; P<0.0001)$, largely driven by maintenance-treatment-naïve GOLD B $(59.8 \%)$ and $\mathrm{C}(63.0 \%)$ patients. Absolute physical functioning scores increased from an average baseline of 44.0 (standard deviation: 25.2) to 54.2 (standard deviation: 26.9) at visit 2. Patients' general condition improved from baseline to visit 2 , and patients were largely satisfied with the Respimat ${ }^{\mathbb{R}}$ inhaler. Adverse events were reported by $7.5 \%$ of patients; the most common were respiratory in nature.

Conclusion: Tiotropium + olodaterol improved physical functioning within 4-6 weeks in patients with moderate-to-very severe COPD. GOLD B and C patients with no prior maintenance treatment demonstrated the greatest benefit.

Keywords: chronic obstructive pulmonary disease, tiotropium, olodaterol, physical functioning, noninterventional, real-world

\section{Introduction}

Bronchodilation, by means of long-acting muscarinic antagonists (LAMAs) and long-acting $\beta_{2}$-agonists (LABAs), is the mainstay of treatment of chronic obstructive pulmonary disease (COPD). Tiotropium, a once-daily LAMA, is widely used in the treatment of COPD and has been shown to improve important disease outcomes. ${ }^{1-6}$ 
Olodaterol is a novel once-daily LABA that has a fast onset of action and a 24-hour bronchodilatory effect, and it has demonstrated symptomatic benefits, enhanced exercise capacity, and improvements in lung function. ${ }^{7,8}$ Current guidelines indicate that combining different classes of bronchodilators, as opposed to increasing the dose of a single drug, may improve efficacy and reduce the risk of side effects. ${ }^{9}$

In a replicate, controlled, randomized clinical trial, a free combination of the two long-acting bronchodilators tiotropium, administered via HandiHaler ${ }^{\circledR}$, and olodaterol, administered via Respimat ${ }^{\circledR}$, resulted in significant improvements in lung function and quality of life over tiotropium + placebo in patients with COPD. ${ }^{10}$ Furthermore, the combination of tiotropium + olodaterol administered via the Respimat $^{\circledR}$ inhaler has been shown to improve lung function, dyspnea, and quality of life, ${ }^{11,12}$ with a comparable incidence of adverse events (AEs) between the combinations and the monocomponents. In those studies that assessed health status, the measurement tool of choice was the St George's Respiratory Questionnaire. In other studies that assessed the impact of bronchodilators on health status in COPD, the 36-item Short Form Health Survey (SF-36) questionnaire has been used. ${ }^{13,14}$ The SF-36 is a general, nondisease-specific instrument for measuring health status. One of the core components of the SF-36 is the self-reported 10-item Physical Functioning Questionnaire (PF-10), which has previously been used in the COPD setting to measure physical functioning improvements following treatment with tiotropium. ${ }^{15}$ The PF-10 constitutes an appropriate measure of physical function/physical activity capacity that can be used in daily clinical practice. ${ }^{16-20}$

Although the efficacy of tiotropium + olodaterol has been documented in controlled trials, more evidence is needed regarding its effectiveness in everyday clinical practice and, indeed, of its translational benefit into improved physical functioning. The aim of this noninterventional study was to assess the effectiveness of the free combination of tiotropium + olodaterol on improving physical functioning in a broad range of patients with COPD treated in primary care.

\section{Materials and methods}

\section{Study design}

This was a prospective, open-label, noninterventional study conducted in Germany between June 2014 and March 2015. In total, 800 nonhospital general practitioners and office-based pulmonary specialists were enrolled. Practices were spread throughout Germany, including both urban and rural areas, to achieve a sample representative of the general population.
Signed patient informed consent was obtained before enrollment. The study was conducted in accordance with the Declaration of Helsinki and the German Medicines Act and was reviewed by the Landesärztekammer Baden-Württemberg institutional review board, Stuttgart, Germany.

\section{Patients and treatments}

The decision to treat was taken independently of participation in the study and was made by the physician before the invitation to participate. Those eligible to participate were patients aged $\geq 40$ years with a physician-made diagnosis of moderate-to-very severe COPD according to Global initiative for chronic Obstructive Lung Disease (GOLD) stages B-D (forced expiratory volume in 1 second $<80 \%$ predicted) in whom combination treatment with two longacting bronchodilators (LAMA + LABA) was indicated in accordance with marketing authorization, summary of product characteristics, and guidelines. According to the real-world approach to this study, there was no requirement for forced expiratory volume in 1 second values to be independently verified by spirometric measurements, and no additional investigations were stipulated. Patients were permitted to be receiving LAMA and/or LABA treatment at study entry. Existing LAMA/LABA treatment was recommended to be discontinued at study entry, and patients were switched to tiotropium + olodaterol without a washout period. Throughout the study period, patients were allowed to continue with any drugs that they took as part of their usual routine treatment, including the use of inhaled corticosteroids (ICS). Exclusion criteria included fulfilling the general and specific contraindications to the study drugs and inclusion in another noninterventional study or clinical trial.

All eligible patients started free combination treatment with tiotropium $5 \mu \mathrm{g}+$ olodaterol $5 \mu \mathrm{g}$ or tiotropium $18 \mu \mathrm{g}+$ olodaterol $5 \mu \mathrm{g}$ once daily (two actuations of $2.5 \mu \mathrm{g}$ ). Tiotropium $5 \mu \mathrm{g}$ and olodaterol $5 \mu \mathrm{g}$ were administered via the Respimat ${ }^{\circledR}$ inhaler, whereas tiotropium $18 \mu \mathrm{g}$ was dispensed via the HandiHaler ${ }^{\circledR}$ (both Boehringer Ingelheim, Ingelheim am Rhein, Germany). After 4-6 weeks of study treatment, patients returned for a second clinic visit. No additional instruction was provided on the use of the inhaler devices that went beyond routine practice training.

\section{End points and assessments} End points

The primary efficacy end point was the percentage of patients who achieved therapeutic success, defined as a 10-point increase in the PF-10 score of the SF-36 between baseline 
and weeks 4-6. This threshold score of a 10-point change was based on the distribution-based method by Cohen. ${ }^{21}$ Based on two 1-year studies conducted in patients with COPD, the baseline standard deviation for physical functioning scores was 22. The minimal important difference ranged between 4 and $11 .{ }^{13}$

Secondary end points included absolute change in PF-10 from visit 1 to the end of the study (visit 2), general condition of the patient (Physicians' Global Evaluation [PGE]) at the initial examination and at the end of the study, and patient satisfaction with the devices used to administer the study drugs. Serious and nonserious AEs were documented.

\section{Visits}

At visit 1 (initial examination), the following variables were recorded: demographics; history of COPD, including last spirometric findings to determine severity; history of smoking; past and present concomitant pulmonary medication; other concurrent diagnoses; and other concomitant medication. The general condition of the patient was assessed by the doctor using an ordinal scale (PGE: 8-point Likert scale from "poor" to "excellent"), and evaluation of the patient's physical functioning was assessed using the self-reported PF-10.

At visit 2, after approximately 4-6 weeks of treatment, PGE and PF-10 assessments were repeated. Patient satisfaction with therapy, overall satisfaction with the Respimat ${ }^{\mathrm{R}}$ inhaler, and satisfaction with handling of the Respimat ${ }^{\mathbb{R}}$ were documented on a 7-point ordinal scale with divisions from "very satisfied" to "very dissatisfied". AEs and treatment discontinuations since the start of treatment for $\leq 30$ days after the end of the noninterventional study were recorded, as were those who continued treatment at visit 2 .

\section{PF- 10}

The PF-10 is a self-reported questionnaire that evaluates whether patients' current state of health limits them in the following activities: vigorous activities (eg, running, lifting heavy objects); moderate activities (eg, moving a table, bowling); lifting or carrying groceries; climbing several flights of stairs; climbing one flight of stairs; bending, kneeling, or stooping; walking $>1 \mathrm{~km}$; walking several hundred meters; walking $100 \mathrm{~m}$; and bathing or dressing oneself.

Item responses were made on a 3-point Likert scale ("Yes, limited a lot", "Yes, limited a little", and "No, not limited at all"). The scores for the 10 items were summed and transformed to a range of $0-100$, with higher scores representing better physical functioning.

\section{Statistical analysis}

All patients in the treated set (any patient who received at least one dose of tiotropium Respimat ${ }^{\circledR} /$ HandiHaler $^{\circledR}+$ olodaterol Respimat ${ }^{\circledR}$ ) were analyzed for tolerability. Patients in the treated set who had a diagnosis of COPD constituted the full analysis set, which was used for analysis of PGE and device-satisfaction results.

For the primary efficacy end point, results were analyzed for the efficacy set (ie, all those in the full analysis set for whom PF-10 values at baseline and weeks 4-6 were available). For all efficacy measures, results were also analyzed in several patient subgroups (ie, GOLD B vs C, D and maintenance naïve vs those previously treated).

Descriptive statistics, including differences from baseline, were prepared for the PF-10 score for all patients and for the subgroups. Differences between the subgroups in therapeutic success rates (measured by PF-10 scores) were analyzed using the $\chi^{2}$ test, and the Wilcoxon signed rank test was used to analyze the difference between the absolute PF-10 scores at baseline and those at weeks 4-6. For estimated therapeutic success rates, $95 \%$ confidence intervals (CIs) were calculated; $P$-values $<0.05$ were considered statistically significant.

\section{Results \\ Patient characteristics}

A total of 1,858 patients were treated during the study: 1,298 $(69.9 \%)$ with tiotropium $5 \mu \mathrm{g}\left(\right.$ Respimat $\left.^{\circledR}\right)+$ olodaterol $5 \mu \mathrm{g}$ $\left(\right.$ Respimat $\left.^{\circledR}\right)$ and 560 patients $(30.1 \%)$ with tiotropium $18 \mu \mathrm{g}$ $\left(\right.$ HandiHaler $\left.^{\circledR}\right)+$ olodaterol $5 \mu \mathrm{g}\left(\right.$ Respimat $\left.^{\circledR}\right)$ (Figure 1). At the end of the study, 1,683 patients $(92.6 \%)$ continued to use tiotropium and 1,556 patients $(85.6 \%)$ continued to use olodaterol. Of the 134 patients who did not continue tiotropium and the 261 patients who did not continue olodaterol after study end, the most common reasons were similar for both: patient decision (69 [51.5\%] tiotropium; 157 [60.2\%] olodaterol), other reasons (23 [17.2\%] tiotropium; 22 [8.4\%] olodaterol), and loss of contact (17 [12.7\%] tiotropium; 18 [6.9\%] olodaterol), and these were similar regardless of treatment assignment during the study period.

Baseline characteristics are reported in Table 1. Mean PF-10 score was 44, and patients with more severe disease had lower physical functioning scores. Most patients had an additional clinical diagnosis other than COPD (76.9\%); cardiac diseases were the most common comorbid conditions (53.0\%). The population was highly treated, with $69.4 \%$ of patients having received other respiratory drugs at baseline, most commonly short-acting $\beta$-agonists $(28.3 \%)$, followed 


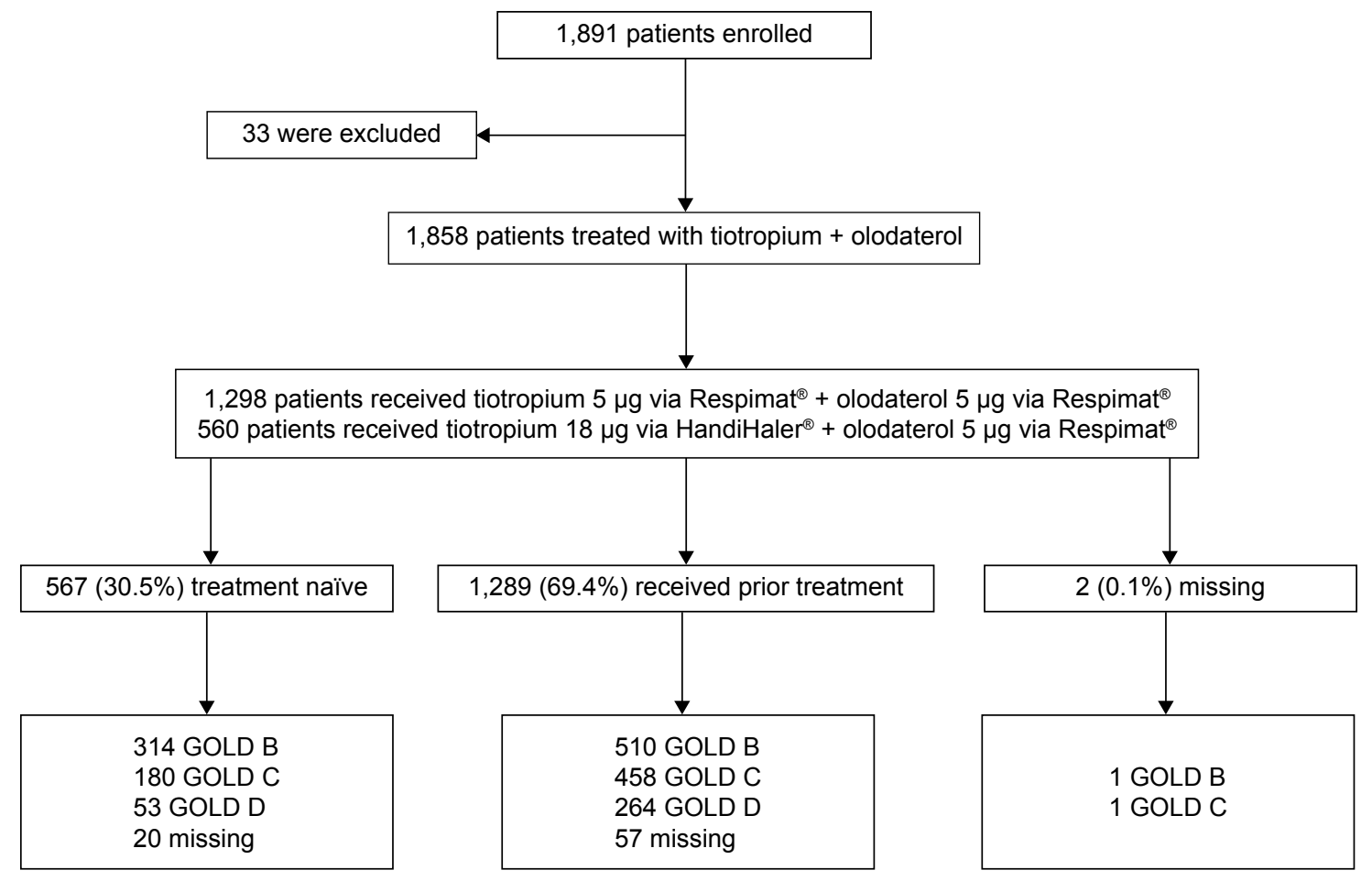

Figure I Patient flow.

Abbreviation: GOLD, Global initiative for chronic Obstructive Lung Disease.

by LABAs (17.4\%) and LABA + ICS combination (21.2\%). Overall, $38.1 \%$ of patients in the GOLD B subgroup were maintenance-treatment-naïve at baseline compared to $28.2 \%$ of GOLD C patients and $16.7 \%$ of GOLD D patients. In total, $16.4 \%$ of GOLD B patients, $22.2 \%$ of GOLD C patients, and $30.3 \%$ of GOLD D patients had received prior LABA/ICS treatment at baseline.

\section{Physical functioning}

Approximately half of all patients $(48.9 \%$; 95\% CI: $46.5,51.3)$ achieved the primary efficacy end point of therapeutic success, defined as a 10-point increase in the physical functioning score (PF-10) between baseline and weeks 4-6 (Figure 2), with an average absolute improvement of 10.2 points $(95 \%$ CI: 9.2,11.1) from visit 1 and visit 2 for all patients (Table 2).

Therapeutic success rates were higher for GOLD B patients compared to GOLD C $(51.2 \%$ vs $48.1 \%$; not significant) or GOLD D $(42.8 \% ; P<0.05)$ and for GOLD C patients vs GOLD D ( $48.1 \%$ vs $42.8 \%$, not significant). Therapeutic success rates were also higher for patients who were maintenance naïve compared to those who had received prior therapy (59.1\% vs $44.5 \% ; P<0.0001$ ), and this was largely driven by a higher percentage of patients with treatment success who were maintenance treatment naïve in the
GOLD B and C subgroups. In contrast, for high-risk patients (GOLD D), the percentage of patients achieving therapeutic success was similar between those who were treatment naïve and those who had received prior therapy. In addition, significant improvements in PF-10 scores were seen in all GOLD subgroups and in maintenance-naïve patients and groups who had received long-acting bronchodilators. Other than GOLD D and prior therapy subgroups, all groups reached the minimal important difference (Table 2). Overall, therapeutic success rates were similar for patients receiving tiotropium $5 \mu \mathrm{g}+$ olodaterol $5 \mu \mathrm{g}$ via the Respimat ${ }^{\circledR}$ inhaler (48.1\%; $95 \%$ CI: $45.2,50.9)$ and those receiving tiotropium $18 \mu \mathrm{g}$ via the HandiHaler ${ }^{\circledR}+$ olodaterol $5 \mu \mathrm{g}$ via the Respimat ${ }^{\circledR}$ inhaler (50.9\%; 95\% CI: 46.5, 55.3; $P=0.285)$.

\section{Patient's general condition and satisfaction}

Patients' general condition, as assessed by PGE score, improved from baseline to visit 2 (Figure 3 ). The proportion of patients categorized as having a "poor" (PGE 1 and 2) general condition fell from $16.8 \%$ at baseline to $6.3 \%$ at visit 2 , and those categorized as "good" (PGE 5 and 6) increased from $26.0 \%$ to $46.1 \%$.

Overall, at visit 2, the majority of patients were either "very satisfied" or "satisfied" with the Respimat ${ }^{\circledR}$ inhaler (Figure 4). 
Table I Baseline patient characteristics

\begin{tabular}{|c|c|}
\hline Variables & Patients \\
\hline \multicolumn{2}{|l|}{ Assigned treatment, $\mathrm{n}(\%)$} \\
\hline Tiotropium $5 \mu \mathrm{g}+$ olodaterol $5 \mu \mathrm{g}$ & $1,298(69.9)$ \\
\hline Tiotropium $18 \mu \mathrm{g}+$ olodaterol $5 \mu \mathrm{g}$ & $560(30.1)$ \\
\hline Mean (SD) age, years & $67.4(10.2)$ \\
\hline Male, $\mathrm{n}(\%)$ & $\mathrm{I}, 088(58.6)$ \\
\hline Current smoker, n (\%) & $656(35.3)$ \\
\hline Mean (SD) COPD duration, years & $6.6(6.3)$ \\
\hline \multicolumn{2}{|l|}{ GOLD disease status, $\mathrm{n}(\%)$} \\
\hline B & $825(44.4)$ \\
\hline C & $639(34.4)$ \\
\hline $\mathrm{D}$ & $317(17.1)$ \\
\hline Mean (SD) exacerbations in past year & I.I (I.4) \\
\hline $\begin{array}{l}\text { Mean (SD) exacerbation-related hospitalizations } \\
\text { in past year }\end{array}$ & $0.2(0.8)$ \\
\hline Further diagnosis, $\mathrm{n}(\%)$ & I,429 (76.9) \\
\hline Cardiac & $984(53.0)$ \\
\hline Vascular & $376(20.2)$ \\
\hline Metabolic/endocrinologic & $590(31.8)$ \\
\hline Taking concomitant medication, $\mathrm{n}(\%)^{\mathrm{a}}$ & $1,167(62.8)$ \\
\hline Cardiac & $837(45.1)$ \\
\hline Metabolic/endocrinologic & $485(26.1)$ \\
\hline Vascular & $269(14.5)$ \\
\hline Gastrointestinal/hepatobiliary & $240(12.9)$ \\
\hline Musculoskeletal/dermatologic & $154(48.3)$ \\
\hline Treatment with other respiratory & $1,289(69.4)$ \\
\hline \multicolumn{2}{|l|}{ therapeutics, $\mathrm{n}(\%)$} \\
\hline LABA & $323(17.4)$ \\
\hline LAMA & $207(I I . I)$ \\
\hline LAMA + LABA combinations & $61(3.3)$ \\
\hline $\mathrm{LABA}+\mathrm{ICS}$ & $393(21.2)$ \\
\hline ICS & $181(9.7)$ \\
\hline SABA & $526(28.3)$ \\
\hline Treatment naïve & $567(30.5)$ \\
\hline Mean (SD) PF-10 score & $44.0(25.2)$ \\
\hline \multicolumn{2}{|l|}{ Mean (SD) PF-10 score stratified } \\
\hline \multicolumn{2}{|l|}{ by disease severity ${ }^{b}$} \\
\hline B & $50.99(24.7)$ \\
\hline C & $41.86(24.2)$ \\
\hline $\mathrm{D}$ & $30.63(22.0)$ \\
\hline
\end{tabular}

Notes: aMultiple answers possible. 'Based on postbronchodilator FEV , percentage predicted.

Abbreviations: SD, standard deviation; COPD, chronic obstructive pulmonary disease; GOLD, Global initiative for chronic Obstructive Lung Disease; LABA, long-acting $\beta_{2}$-agonist; LAMA, long-acting muscarinic antagonist; ICS, inhaled corticosteroid; SABA, short-acting $\beta$-agonist; PF-10, 10-item Physical Functioning Questionnaire; $\mathrm{FEV}_{1}$, forced expiratory volume in I second.

Findings were virtually identical for patient satisfaction with the handling of the device (data not shown).

\section{Safety}

Patients were exposed to study medication for a mean (standard deviation) of 38 (16.7) days; the median exposure was 35 days. In total, 139 of the 1,858 patients in the treated set (7.5\%) reported an $\mathrm{AE}$ during the observation period (Table 3), and 137 patients had events that emerged following

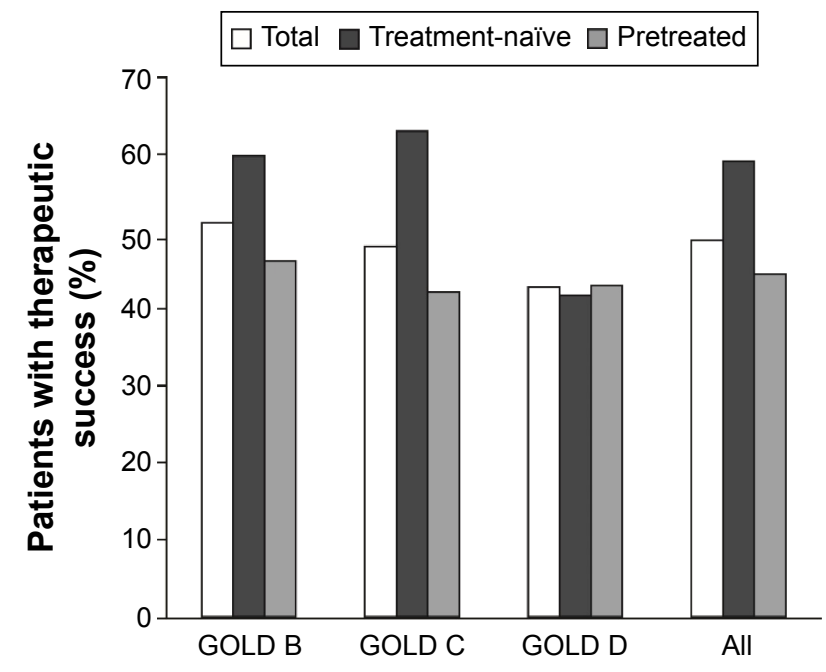

Figure 2 Therapeutic success in all patients and stratified by GOLD subgroups and prior maintenance treatment.

Notes: $n=1,726$ (efficacy set) for prior treatment comparison. Not significant: treatment-naïve GOLD B vs GOLD C; GOLD D treatment-naïve vs pretreated; total GOLD B vs total GOLD C; total GOLD C vs total GOLD D. $P<0.05$ : treatment-naïve GOLD B vs GOLD D; total GOLD B vs total GOLD D. $P<0.01$ : treatment-naïve GOLD C vs GOLD D. $P<0.00$ I: GOLD B treatment-naïve vs pretreated. $P<0.000$ I: treatment-naïve All vs pretreated All; GOLD C treatment-naïve vs pretreated. Abbreviation: GOLD, Global initiative for chronic Obstructive Lung Disease.

the initiation of treatment (treatment-emergent AEs). In total, 59 patients (3.2\%) had AEs that led to discontinuation of treatment. Infections and infestations (37 patients, $2.0 \%$ ) and respiratory, thoracic, and mediastinal disorders (46 patients, $2.5 \%)$ were the most common treatment-emergent AEs. Seven $(0.4 \%)$ and $44(2.4 \%)$ patients had at least one treatment-emergent $\mathrm{AE}$ that was deemed to be causally related to tiotropium and olodaterol, respectively. There were 35 patients who reported a total of 42 serious treatment-emergent AEs. The most common was COPD $(28.6 \%$ of patients with serious treatment-emergent $\mathrm{AE})$, and hospitalization was most often documented as the reason for seriousness ( 29 cases, $69.1 \%$ of cases). Eight of the serious treatmentemergent AEs were fatal, reported as metastatic bronchial carcinoma, respiratory failure, aspiration, cardiac arrest, sudden cardiac death, death (two cases), and myocardial infarction. No patient had a serious treatment-emergent $\mathrm{AE}$ with causal relationship to study medication.

\section{Discussion}

This is the first study to assess the efficacy of the free combination of tiotropium + olodaterol in a large patient population in a real-world clinical setting. We found that in a typical outpatient COPD population, tiotropium + olodaterol confers a clinically meaningful benefit in physical functioning after 4-6 weeks of treatment. The beneficial effects for the primary efficacy end point translated into improvements in patients' 
Table 2 Physical functioning (PF-10) scores at visits I and 2, and change from baseline

\begin{tabular}{|c|c|c|c|c|}
\hline & Visit I, mean (SD) & Visit 2, mean (SD) & Change score, mean (SD) & $P$-value \\
\hline All patients & $44.03(25.18)$ & $54.17(26.93)$ & 10.15 (19.22) & $<0.0001$ \\
\hline GOLD B & $50.99(24.73)$ & $61.34(24.90)$ & $10.34(19.21)$ & $<0.000$ I \\
\hline Pretreated & $51.64(25.07)$ & $59.00(24.63)$ & $7.36(18.51)$ & \\
\hline Naïve & $50.03(24.16)$ & $65.30(24.85)$ & $15.27(19.40)$ & \\
\hline GOLD C & $41.86(24.17)$ & $52.4 I(26.38)$ & $10.55(19.36)$ & $<0.000$ I \\
\hline Pretreated & $40.60(24.16)$ & $48.28(25.98)$ & $7.68(17.85)$ & \\
\hline Naïve & $45.22(23.97)$ & $62.96(24.50)$ & I7.74 (2I.0I) & \\
\hline GOLD D & $30.63(21.95)$ & $38.10(25.30)$ & $7.47(17.78)$ & $<0.0001$ \\
\hline Pretreated & $30.66(2 I .4 I)$ & $37.23(24.65)$ & $6.56(16.7 \mathrm{I})$ & \\
\hline Naïve & $30.47(24.72)$ & $42.53(28.25)$ & I2.07 (22.07) & \\
\hline Maintenance naïve & $46.57(24.95)$ & $62.35(25.83)$ & I5.78 (20.35) & $<0.0001$ \\
\hline LABD & $42.93(25.24)$ & $50.64(26.62)$ & $7.71(18.19)$ & $<0.000$ I \\
\hline
\end{tabular}

Abbreviations: PF-10, 10-item Physical Functioning Questionnaire; SD, standard deviation; GOLD, Global initiative for chronic Obstructive Lung Disease; LABD, long-acting bronchodilator.

general condition, as demonstrated by an improvement in the distribution of the physician-completed PGE scale scores. In addition, the majority of patients were either "satisfied" or "very satisfied" with using the Respimat ${ }^{\circledR}$ inhaler.

The findings of this real-world investigation complement those of a recent replicate, double-blind, randomized, 12 -week study of a free combination of tiotropium + olodaterol vs tiotropium + placebo in patients with GOLD 2-3 COPD.$^{10}$ In this study, conducted in 2,267 patients, improvements in lung function and St George's Respiratory Questionnaire activity subscore were observed in controlled settings for those treated with tiotropium + olodaterol. ${ }^{10}$ Our study adds to these findings by showing that tiotropium + olodaterol confers benefits for physical functioning.

In addition to an observational study investigating the effectiveness of tiotropium $5 \mu \mathrm{g}$ on the self-reported PF-10

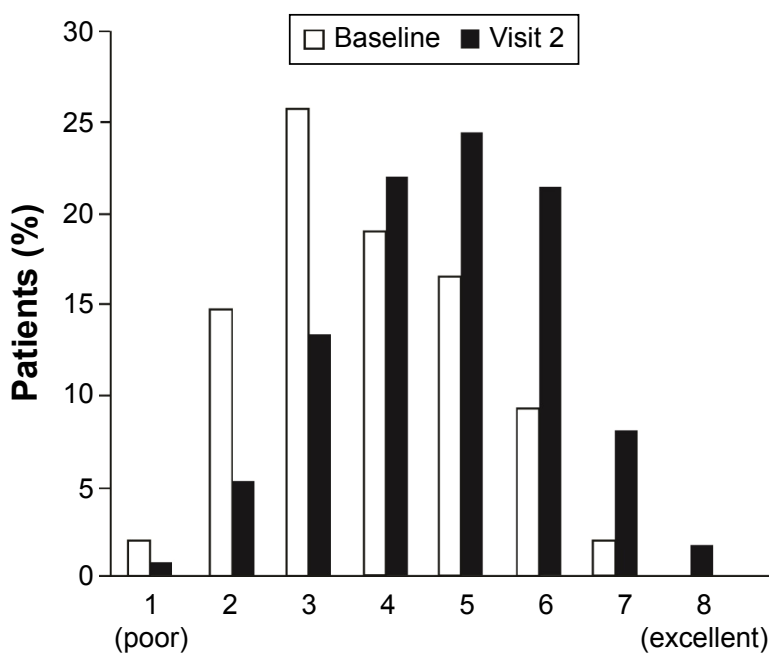

Figure 3 General condition of patients (Physicians' Global Evaluation) at baseline and visit 2 (all patients).

Note: $\mathrm{n}=\mathrm{I}, 854$ (baseline); $\mathrm{n}=\mathrm{I}, 8 \mathrm{I} 3$ (visit 2) (full analysis set). in treatment-naïve patients with COPD,${ }^{15}$ we found a greater success rate for patients with GOLD B and C disease who were treatment naïve compared to those who had prior medication with bronchodilators and/or ICS. In contrast, for high-risk patients (GOLD D), we found no difference in the percentage of patients achieving therapeutic success between those who were maintenance naïve or were pretreated. This may reflect the more advanced disease state of these patients and more severe condition at baseline, and the higher proportion of pretreated vs maintenance-naïve patients. This result is also in line with that of a post hoc analysis of combined tiotropium + olodaterol vs monocomponents in COPD studies, which found the greatest therapeutic benefits among those patients with less severe disease, adding support for

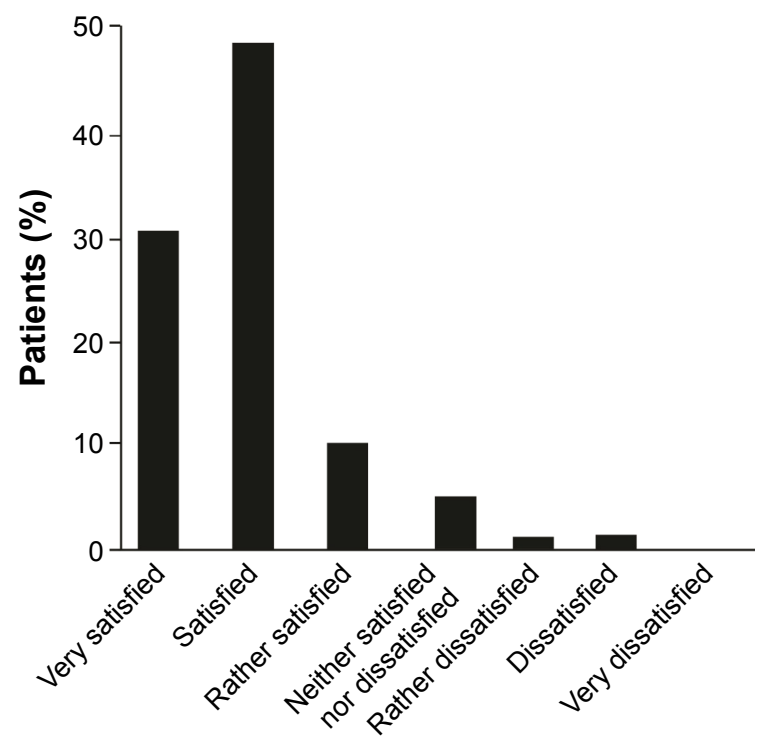

Figure 4 Overall patient satisfaction with the Respimat ${ }^{\circledR}$ inhaler.

Note: Patient satisfaction with the handling of the Respimat ${ }^{\circledR}$ inhaler followed a virtually identical pattern to the overall satisfaction data; $n=|, 8| 3$. 
Table 3 Summary of AEs

\begin{tabular}{ll}
\hline AE category & Patients, n (\%) \\
\hline AEs & $139(7.5)$ \\
Treatment-emergent AEs & $137(7.4)$ \\
Serious AEs & $36(1.9)$ \\
Serious treatment-emergent AEs & $35(1.9)$ \\
Treatment-emergent AEs leading & $59(3.2)$ \\
to discontinuation & \\
AEs with deadly outcome & \\
\hline
\end{tabular}

Note: Metastatic bronchial carcinoma, respiratory failure, aspiration, cardiac arrest, sudden cardiac death, death (2 cases), and myocardial infarction.

Abbreviation: $\mathrm{AE}$, adverse event.

the early use of combined bronchodilation in the treatment of patients with symptomatic COPD. ${ }^{22}$

We used the self-reported PF-10, a component of the SF-36, as a measure of physical functioning. It is recognized that self-reported measures have limitations, namely social desirability and recall biases. ${ }^{23,24}$ That said, we found that patients with more severe disease had lower physical functioning at baseline, suggesting that the PF-10 differentiates well between patients of varying disease severity, which provides further evidence for its use as a suitable tool for assessing change in physical functioning in patients with COPD..$^{15,20}$

The incidence of AEs in this study population was consistent with other trials of tiotropium + olodaterol; ${ }^{10,11}$ however, the rates at which these events occurred were lower in the present study, though it should be noted that this result rather reflects the less stringent reporting of AEs in observational studies compared to randomized clinical trials. Serious AEs including death were judged to be unrelated to study medication.

Mode of drug administration is an important consideration for patients with COPD, as the use of multiple devices may affect adherence. Patients in this study were largely satisfied with the therapy and mode of drug delivery, reflected by the high percentage who continued treatment after the observation period ended ( $92.6 \%$ for tiotropium and $85.6 \%$ for olodaterol). Our findings support those of Hanada et al's study, ${ }^{25}$ in which most patients preferred the Respimat ${ }^{\circledR}$ compared to the HandiHaler ${ }^{\circledR}$.

The findings of this study should be viewed in light of its limitations. This was an open-label, nonrandomized study using an observational design over a short period of time. The measures of physical functioning and patient general condition were subjective, and whether improvement of physical functioning can be maintained over a longer period of time requires further study. Furthermore, it was not possible to control for concomitant medications being taken by patients or to assess patient adherence to the drug regimen, and so it is not known what effect these variables may have had on efficacy or safety. Study strengths include the realworld primary-care setting, the participation of numerous practice-based physicians, and the inclusion of a large representative sample of patients with a wide spectrum of COPD severities, treatments, and comorbidities, thus avoiding the specific exclusion and inclusion criteria regarding comorbidities and treatment seen with randomized trials. ${ }^{26,27}$

In summary, this observational study showed that oncedaily treatment with a free combination of the LAMA tiotropium and the LABA olodaterol rapidly improved physical functioning and general condition over a broad range of disease severities in patients with COPD. GOLD B and C patients who were maintenance treatment naïve demonstrated the greatest benefit. Our findings provide real-world data from a primary care setting, thereby complementing the body of literature on which to base the choice of longacting bronchodilator therapy for the maintenance treatment of COPD. However, further prospective trials are needed to further support the role of LAMA/LABA combinations within the COPD treatment algorithm.

\section{Acknowledgments}

The authors received no compensation related to the development of the manuscript. Medical writing assistance was provided by David McMinn, PhD, of Complete HealthVizion, which was contracted and compensated by Boehringer Ingelheim Pharma GmbH \& Co. KG.

\section{Author contributions}

All authors made substantial contributions to conception and design, acquisition of data, or analysis and interpretation of data; took part in either drafting the article or revising it critically for important intellectual content; gave final approval of the version to be published; and agree to be accountable for all aspects of the work.

\section{Disclosure}

Roland Buhl has received personal fees from AstraZeneca, Chiesi, GlaxoSmithKline, and Takeda; and has received grants and personal fees from Boehringer Ingelheim, Novartis, and Roche. Michaela Hänsel and Thomas Glaab are employees of Boehringer Ingelheim Pharma GmbH \& Co. KG. The authors report no other conflicts of interest in this work.

\section{References}

1. Bateman ED, Tashkin D, Siafakas N, et al. A one-year trial of tiotropium Respimat $^{\circledR}$ plus usual therapy in COPD patients. Respir Med. 2010; 104(10):1460-1472. 
2. Cooper CB, Celli BR, Jardim JR, et al. Treadmill endurance during 2-year treatment with tiotropium in patients with COPD: a randomized trial. Chest. 2013;144(2):490-497.

3. Tashkin DP, Celli B, Senn S, et al. A 4-year trial of tiotropium in chronic obstructive pulmonary disease. N Engl J Med. 2008;359(15): 1543-1554.

4. Vogelmeier C, Hederer B, Glaab T, et al. Tiotropium versus salmeterol for the prevention of exacerbations of COPD. $N$ Engl J Med. 2011; 364(12):1093-1103.

5. Wise RA, Anzueto A, Cotton D, et al. Tiotropium Respimat inhaler and the risk of death in COPD. N Engl J Med. 2013;369(16):1491-1501.

6. Yohannes AM, Willgoss TG, Vestbo J. Tiotropium for treatment of stable COPD: a meta-analysis of clinically relevant outcomes. Respir Care. 2011;56(4):477-487.

7. Deeks ED. Olodaterol: a review of its use in chronic obstructive pulmonary disease. Drugs. 2015;75(6):665-673.

8. Roskell NS, Anzueto A, Hamilton A, Disse B, Becker K. Once-daily long-acting beta-agonists for chronic obstructive pulmonary disease: an indirect comparison of olodaterol and indacaterol. Int J Chron Obstruct Pulmon Dis. 2014;9:813-824.

9. Global Initiative for Chronic Obstructive Lung Disease. Global strategy for the diagnosis, management, and prevention of chronic obstructive pulmonary disease [updated February 18, 2015]. Available from: http:// www.goldcopd.org/uploads/users/files/GOLD_Report_2015_Feb18. pdf. Accessed September 30, 2015.

10. ZuWallack R, Allen L, Hernandez G, Ting N, Abrahams R. Efficacy and safety of combining olodaterol Respimat ${ }^{\circledR}$ and tiotropium HandiHaler ${ }^{\circledR}$ in patients with COPD: results of two randomized, doubleblind, active-controlled studies. Int J Chron Obstruct Pulmon Dis. 2014;9:1133-1144

11. Buhl R, Maltais F, Abrahams R, et al. Tiotropium and olodaterol fixeddose combination versus mono-components in COPD (GOLD 2-4). Eur Respir J. 2015;45(4):969-979.

12. Singh D, Ferguson GT, Bolitschek J, et al. Tiotropium + olodaterol shows clinically meaningful improvements in quality of life. Respir Med. 2015;109(10):1312-1319.

13. Casaburi R, Mahler DA, Jones PW, et al. A long-term evaluation of once-daily inhaled tiotropium in chronic obstructive pulmonary disease. Eur Respir J. 2002;19(2):217-224.

14. Vincken W, van Noord JA, Greefhorst APM, et al. Improved health outcomes in patients with COPD during 1 yr's treatment with tiotropium. Eur Respir J. 2002;19(2):209-216.
15. Rau-Berger H, Mitfessel H, Glaab T. Tiotropium Respimat ${ }^{\circledR}$ improves $^{-}$ physical functioning in chronic obstructive pulmonary disease. Int J Chron Obstruct Pulmon Dis. 2010;5:367-373.

16. Glaab T, Vogelmeier C, Buhl R. Outcome measures in chronic obstructive pulmonary disease (COPD): strengths and limitations. Respir Res. 2010;11:79.

17. Brazier JE, Harper R, Jones NM, et al. Validating the SF-36 health survey questionnaire: new outcome measure for primary care. $B M J$. 1992;305(6846):160-164.

18. Ware JE Jr, Sherbourne CD. The MOS 36-item short-form health survey (SF-36). I. Conceptual framework and item selection. Med Care. 1992; 30(6):473-483

19. Ware JE Jr, Gandek B. Overview of the SF-36 Health Survey and the International Quality of Life Assessment (IQOLA) Project. J Clin Epidemiol. 1998;51(11):903-912.

20. Gummesson C, Atroshi I, Ekdahl C. Performance of health-status scales when used selectively or within multi-scale questionnaire. BMC Med Res Methodol. 2003;3:3.

21. Cohen J. Statistical Power Analysis for the Behavioral Sciences. 2nd ed. Hillsdale, NJ: Lawrence Erlbaum Associates; 1988.

22. Ferguson GT, Fležar M, Korn S, et al. Efficacy of tiotropium + olodaterol in patients with chronic obstructive pulmonary disease by initial disease severity and treatment intensity: a post hoc analysis. Adv Ther. 2015; 32(6):523-536.

23. Arp Adams S, Matthews CE, Ebbeling CB, et al. The effect of social desirability and social approval on self-reports of physical activity. Am J Epidemiol. 2005;161(4):389-398.

24. Welk GJ, Kim Y, Stanfill B, et al. Validity of 24-h physical activity recall: physical activity measurement survey. Med Sci Sports Exerc. 2014;46(10):2014-2024.

25. Hanada S, Wada S, Ohno T, Sawaguchi H, Muraki M, Tohda Y. Questionnaire on switching from the tiotropium HandiHaler to the Respimat inhaler in patients with chronic obstructive pulmonary disease: changes in handling and preferences immediately and several years after the switch. Int J Chron Obstruct Pulmon Dis. 2015;10:69-77.

26. Concato J, Shah N, Horwitz RI. Randomized, controlled trials, observational studies, and the hierarchy of research designs. $N$ Engl J Med. 2000;342(25):1887-1892.

27. Michel MC, Goepel M. Treatment satisfaction of patients with lower urinary tract symptoms: randomised controlled trials vs. real life practice. Eur Urol. 2000;38(Suppl 1):40-47.
International Journal of COPD

\section{Publish your work in this journal}

The International Journal of COPD is an international, peer-reviewed journal of therapeutics and pharmacology focusing on concise rapid reporting of clinical studies and reviews in COPD. Special focus is given to the pathophysiological processes underlying the disease, intervention programs, patient focused education, and self management protocols.
Dovepress

This journal is indexed on PubMed Central, MedLine and CAS. The manuscript management system is completely online and includes a very quick and fair peer-review system, which is all easy to use. Visit http://www.dovepress.com/testimonials.php to read real quotes from published authors. 